Author's post-print: A. Alonso-Estébanez, J.J. Del Coz Díaz, F.P. Álvarez Rabanal, P. Pascual-Muñoz. "Performance analysis of wind fence models when used for truck protection under crosswind through numerical modelling". Journal of Wind Engineering \& Industrial Aerodynamics 168 (2017) 20-31. DOI: 10.1016/j.jweia.2017.04.021

\title{
Performance analysis of wind fence models when used for truck protection under crosswind through numerical modelling
}

\author{
A. Alonso-Estébanez ${ }^{1, *}$, J.J. Del Coz Díaz², F.P. Álvarez Rabanal ${ }^{3}$, P. Pascual-Muñoz ${ }^{4}$
}

${ }^{1}$ Dept. of Transport, Project and Process Technology, ETSICCP, Univ. of Cantabria, Ave. Castros s/n, 39005 Santander, Spain. Email: alonsoea@unican.es.

${ }^{2}$ Dept. of Construction, EPSIG, Univ. of Oviedo, Departmental Building 7, 33204 Gijón, Spain. E-mail: juanjo@constru.uniovi.es. ${ }^{3}$ Dept. of Construction, EPSIG, Univ. of Oviedo, Departmental Building 7, 33204 Gijón, Spain. E-mail: felipe@constru.uniovi.es. ${ }^{4}$ Dept. of Transport, Project and Process Technology, ETSICCP, Univ. of Cantabria, Ave. Castros s/n, 39005 Santander, Spain. Email: pascualmp@unican.es.

\section{Abstract}

This paper is focused on truck aerodynamic analysis under crosswind conditions by means of numerical modelling. The truck was located on the crest of an embankment during the study. In order to analyze the performance of three wind fence models, the truck's aerodynamic coefficients were obtained and compared in two different situations either with or without the wind fences installed. In addition, the effect of both height and porosity of wind fence models on the aerodynamic coefficients acting on truck with respect to separation distance between the truck and the wind fence, was analyzed. A finite volume (or computational fluid dynamic) code was used to carry out the numerical modeling. The Reynoldsaveraged Navier-Stokes (RANS) equations along with the $k-\omega$ SST turbulence model were used to predict the behavior of turbulent flow. With respect to the results, the influence of the distance on the rollover coefficient is soft for all height values studied except for the lowest value (1m of fence height), where the maximum value of rollover coefficient was obtained for the truck position closer to the fence. Regarding fence porosity, its effect on rollover coefficient is stronger for truck positions on road closer to the wind fence model.

Keywords: Crosswind; truck vehicle aerodynamics; wind fence; embankment; CFD simulations; wind tunnel tests.

\section{Introduction}

Under strong crosswind conditions, vehicle stability is adversely affected and as a consequence the risk of having an accident is increased. This issue has motivated the development of wind warning systems (Hoppmann et al., 2002; Delaunay et al., 2006) and new guidelines/regulations (Tielkes et al., 2008; Imai 4 et al., 2002) in order to safeguard crosswind safety. With this goal, wind fences have also been used in bridges and embankments as in Imai et al. (2002). Another aspect is that blowing snow hinders driving because the drivers' visibility is reduced and ice formation is caused (Tabler and Meena, 2007; Matsuzawa et al., 2005). Thus, in exposed windy and snowy locations, wind fences have been adopted as control measures for protecting roads. In different locations around the world several accidents due to crosswind and blowing snow have been registered and analyzed (Imai et al., 2002; Shao et al., 2011; Matsuzawa et al., 2005).

*Corresponding author. Tel.: +34 942 200894; fax: +34 942201703. 
There are many works on wind fence performance within other fields of application apart from traffic safety. Bitog et al. (2009) analyzed the effect of different building parameters of wind fences on preventing the generation and diffusion of dust from sandy land. In open storage yards, the stockpiles are often eroded by the wind and as countermeasures are needed to avoid the dispersion of particles, wind fences are used in many locations (Yeh et al., 2010; Santiago et al., 2007; Park and Lee, 2001). Trees may also be used as windbreaks to prevent odour dispersion in places like livestock farms (Lin et al., 2007). Another application of wind fences is aimed at improving external comfort in urban open spaces such as parks, playgrounds and recreational fields (Li et al., 2007).

Some studies have focused on optimizing different parameters of the snow fence geometry to improve its performance. Dong et al. (2007) studied the influence of porosity on the fence's shelter efficiency, measuring wind velocity and analyzing streamline patterns behind the fence. This research found that the optimal porosity was around 0.2 or 0.3 , since for higher values of porosity, bleed flow dominates and for lower values of porosity, reversed flow becomes significant. Other parameters such as wind fence height and gap between the ground and the fence have been also studied. Kim and Lee (2002) investigated the flow field behind porous fences for four values of gap ratios, and the best protection against the wind was found for a gap ratio of $0.1 \mathrm{H}$ ( $\mathrm{H}$ being the height of the fence). Imai et al. (2002) obtained the aerodynamic coefficients of a vehicle through wind tunnel test for several values of the height and porosity of the fence. The result indicated that for higher height of fence, keeping the porosity constant, the possibilities of overturning diminished. The influence of the distance between the vehicles and a wind fence model consisted of boards on the aerodynamics coefficient of rail and road vehicles, was studied in Zhu et al. (2012) for four positions of vehicle along the cross section of bridge. Also, Guo et al. (2015) estimated the aerodynamic coefficients acting on rail vehicle with different wind fence configurations installed on a bridge for two positions of vehicle on the bridge (windward and leeward). In both studies, the aerodynamic coefficients of vehicles diminished with the distance between the vehicle and the wind fence.

So far, wind fence performance has been evaluated by different techniques such as numerical simulation (CFD), wind tunnel test and field experiments. Wind tunnel tests were carried out to investigate how the wind fence improves vehicle stability under cross wind conditions when a vehicle passes through the wake of a bridge tower (Agentini et al., 2011; Bocciolone et al., 2008). For instance, Santiago et al. (2007) used numerical simulation in addition to wind tunnel tests in order to determine an optimum porosity for sheltering effect of an isolated windbreak. While other research such as Tuzet and Wilson (2007) and Torita and Satou (2007) performed field studies about the wind shelter provided by natural windbreaks.

In this paper, shelter efficiency of three wind fence models installed on an embankment is analyzed by obtaining the aerodynamic coefficients acting on the truck. Particularly, the first aim of this research consists in analyzing the influence of the geometry design of wind fences on truck aerodynamics. The second aim is to demonstrate the use of CFD codes to solve this kind of problems, being validated with experimental data. On the other hand, the first part of the paper describes the methodology applied to 
carry out the numerical simulations and the second section indicates and discusses the main results of the study. The last section specifies the main conclusions based on the results obtained.

\section{Numerical procedure}

The ANSYS FLUENT Academic Research software version 15 was used for solving the fluid-structure interaction problem.

\subsection{Formulation of the model}

The CFD codes numerically solve the governing equations of a turbulent flow, which are the continuity equation and Reynolds average Navier-Stokes (RANS) momentum, equation indicated in Eq. (1) and Eq. (2) (Mathieu and Scott, 2000; Pope, 2000; Tu et al., 2008). In order to obtain these equations, the Reynolds decomposition was used.

$$
\begin{gathered}
\frac{\partial \bar{u}_{i}}{\partial x_{i}}=0 \\
\frac{\partial}{\partial t}\left(\rho \bar{u}_{i}\right)+\frac{\partial}{\partial x_{j}}\left(\rho \bar{u}_{i} \bar{u}_{j}\right)=-\frac{\partial \bar{p}}{\partial x_{i}}+\frac{\partial}{\partial x_{j}}\left[\mu\left(\frac{\partial \bar{u}_{i}}{\partial x_{j}}+\frac{\partial \bar{u}_{j}}{\partial x_{i}}\right)-\rho{\overline{u_{i}^{\prime} u_{j}^{\prime}}}_{j}\right]
\end{gathered}
$$

The term $-\rho \overline{u_{i}^{\prime} u_{j}^{\prime}}$ is a turbulent stress or Reynolds stress and states the correlations among the fluctuating velocity components. This term depicts additional unknowns in the time-averaged NavierStokes momentum equation. Therefore, for closing the above system of equations, new expressions which model the Reynolds stresses are required. These expressions will be introduced by mean of called turbulence models.

The SST $k-\omega$ turbulence model (Menter 1993, 1994) was used in the present work because it provides good performance when dealing with low Reynolds issues, adverse pressure gradients and separating flow regions. This turbulence model combines the standard $k-\varepsilon$ model and the $k-\omega$ model, which retains the properties of $k-\omega$ close to the wall and gradually blends into the standard $k-\varepsilon$ model away from the wall. Nevertheless, the numerical results were also obtained by using the standard $k-\varepsilon$ model in order to check the better performance of SST $k-\omega$ to estimate the aerodynamic loads acting on the truck model analysed. The standard $k-\varepsilon$ model was selected because it is the most widely validated turbulence model and used for industrial applications (Andersson et al., 2011; Ranade, 2002). The standard Menter SST two-equation model (written in conservation form) is provided by the following two equations, the first equation corresponding to the turbulence kinetic energy, $k$, and the second equation for the specific dissipation rate, $\omega$ :

$$
\begin{gathered}
\frac{\partial k}{\partial t}+\overline{u_{j}} \frac{\partial k}{\partial x_{j}}=P_{k}-\beta^{*} k \omega+\frac{\partial}{\partial x_{j}}\left[\left(v+\sigma_{k} v_{T}\right) \frac{\partial k}{\partial x_{j}}\right] \\
\frac{\partial \omega}{\partial t}+\overline{u_{j}} \frac{\partial \omega}{\partial x_{j}}=\alpha S^{2}-\beta \omega^{2}+\frac{\partial}{\partial x_{j}}\left[\left(v+\sigma_{\omega 1} v_{T}\right) \frac{\partial \omega}{\partial x_{j}}\right]+2\left(1-F_{1}\right) \sigma_{\omega 2} \frac{1}{\omega} \frac{\partial k}{\partial x_{i}} \frac{\partial \omega}{\partial x_{i}}
\end{gathered}
$$


The equations have been written to be in an appropriate conservation form (Zienkiewicz et al., 2005). Note that it is generally recommended to use a production limiter for the turbulence kinetic energy. Therefore, in this research work, the term $P_{k}$ in the Eq. (3) is replaced by:

$$
P_{k}=\min \left(\overline{\tau_{i j}} \frac{\partial \overline{u_{i}}}{\partial x_{j}}, 10 \beta^{*} k \omega\right)
$$

Where the stress tensor, $\overline{\tau_{i j}}$, can be written as:

$$
\overline{\tau_{i j}}=\mu_{T}\left(2 S_{i j}-\frac{2}{3} \frac{\partial \overline{u_{k}}}{\partial x_{k}} \delta_{i j}\right)-\frac{2}{3} \rho k \delta_{i j}
$$

and the kinematic eddy viscosity is computed from:

$$
v_{T}=\frac{a_{1} k}{\max \left(a_{1} \omega, \Omega F_{2}\right)} .
$$

More detailed information about constants or closure coefficients can be found in Menter (1993), (1994) and Ansys, (2015).

\subsection{Wind fence models and aerodynamic coefficients}

The embankment configuration, as shown in Fig. 1, speeds up the air flow on the windward slope (Bitsuamlak et al., 2004). Therefore, in this situation the vehicles are more likely to suffer a rollover accident than in other locations for a specific yaw angle (angle between relative wind speed and path of vehicle) range (Schober et al., 2010). Accordingly, the embankment configuration is a scenario where the security of traffic could be significantly improved by installing wind fences. This was the reason for choosing this scenario to carry out the study about performance of three models of wind fences (Fig. 1). In the numerical simulation, the models (wind fences, embankment and truck) were scaled down 1/10 with respect to the full scale prototype as in Cheli et al. (2011alb). Detailed information about the dimensions of both the truck and embankment can be found in Cheli et al. (2011a) and Cheli et al. (2011b) respectively. Specifically, the aerodynamic coefficient acting on truck was obtained for a wind fence with plates and two wind fences with different shapes of the open area (circular and rectangular). Also, the aerodynamic loads were calculated for the truck located on the embankment without protection. This case is based on the wind tunnel test developed by Cheli et al. (2011b), allowing analyze the goodness of fit between the numerical model and an experimental reference. Therefore, this case was solved previously to the models including the different wind fence types studied.

\subsection{Aerodynamic forces and moments}

Particularly, the following aerodynamic forces and moments were obtained: side force $\left(F_{S}\right)$, lift force $\left(F_{L}\right)$ and rollover moment $\left(M_{R}\right)$ (Fig. 2). The side and lift forces acting on the truck were calculated by integrating the pressure distribution over the surface of truck. The rollover moment is the sum of the moments from the side and the lift force above point $\mathrm{O}$. 

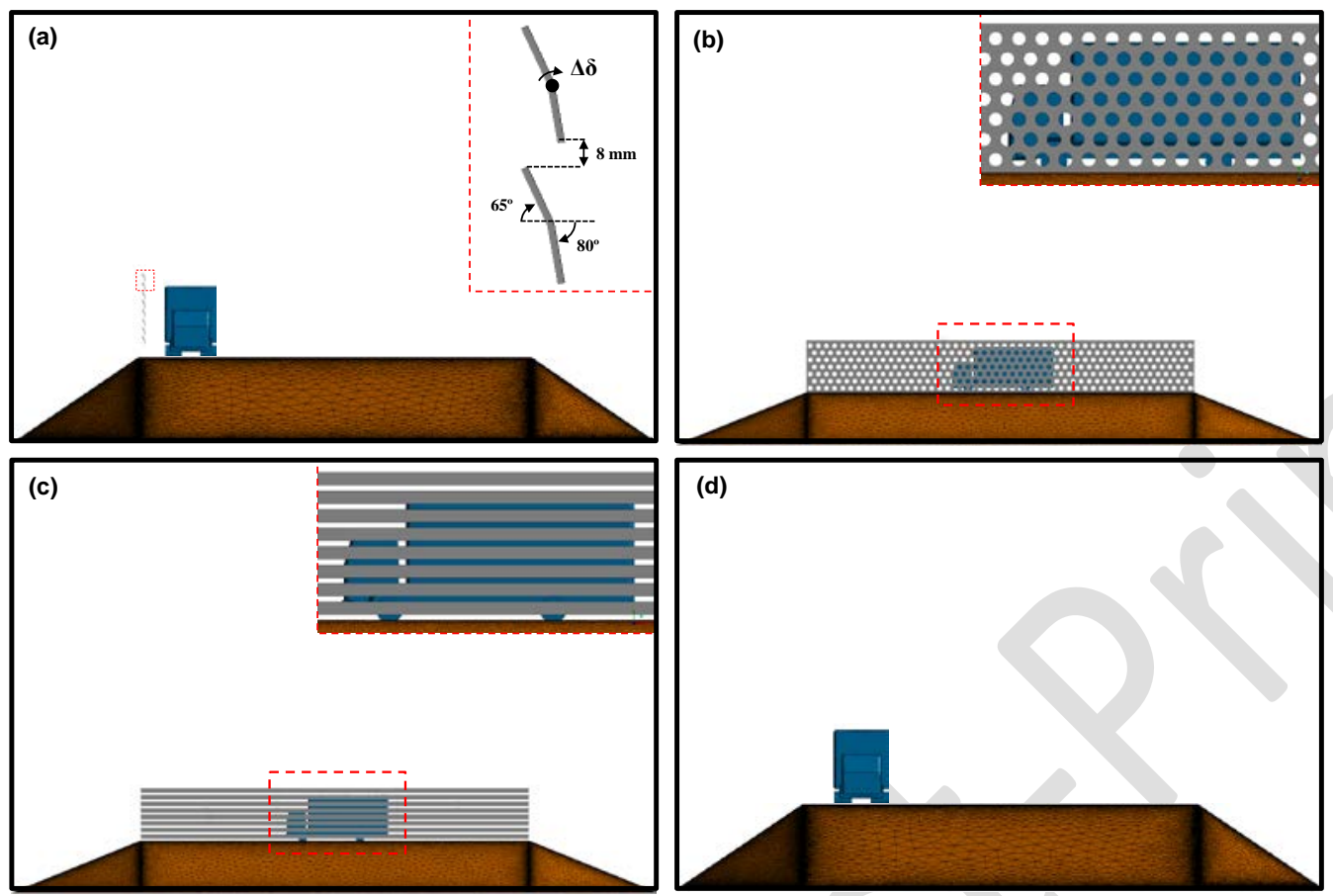

Fig. 1. Models studied (1:10 scale): (a) Wind fence model with plates; (b) Wind fence model with circular holes; (c) Wind fence model with rectangular slits and (d) Without wind fence model.

139 Once the aerodynamic loads were calculated, they were rendered dimensionless coefficients using the 140 following expressions:

$$
C_{S}=\frac{F_{S}}{\frac{1}{2} \rho U^{2} A_{S}} \quad C_{L}=\frac{F_{L}}{\frac{1}{2} \rho U^{2} A_{S}} \quad C_{R}=\frac{M_{R}}{\frac{1}{2} \rho U^{2} A_{S} H}
$$

where $\rho$ is the density of the air, $A_{S}$ is the side area of the truck, $H$ is the reference height (height of box truck) and $U$ is the mean streamwise wind speed measured at $0.6 \mathrm{~m}$ from the ground in the CFD model. Both the truck model and the embankment studied in these CFD models have the same dimensions of the 1:10 scale model presented in Cheli et al. (2011alb).

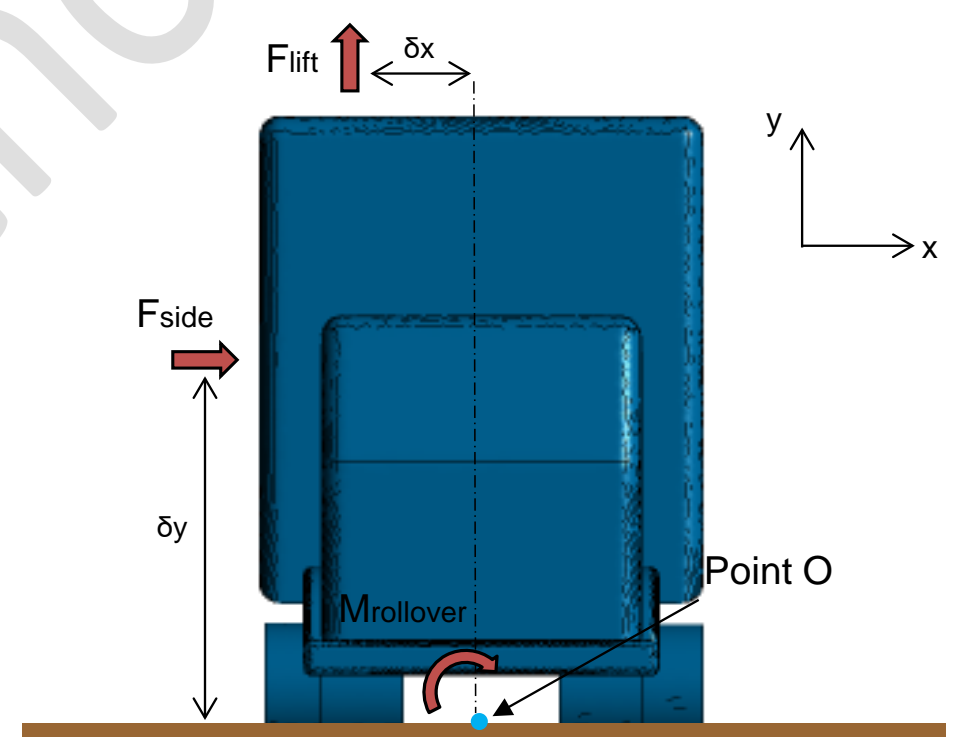

Fig. 2. Sketch of aerodynamic loads studied under crosswind conditions. 


\subsection{Grid, boundary conditions and design of experiment}

148

149

150

151

152

153

154

155

156

157

158

159

160

161

162

163

164

165

166

167

168

169

170

171

172

The 3D geometry for the computational domain defined to solve the fluid behavior around the bluff bodies (truck, wind fences and embankment) is shown in Fig. 3. The inlet and outlet of air flow were located at least $8.3 H_{o b s}$ (being $H_{o b s}$ the obstacle height) and $19.3 H_{o b}$ from the bluff bodies respectively for the studied cases. The cross section keeps the same dimensions of boundary layer test section of Polytechnic of Milano, $14 \mathrm{~m} \mathrm{x} 4 \mathrm{~m}$ (Bocciolone et al., 2008). On the other hand, three sub-domains (near domain and two far domains) compose the air region solved with the objective of setting different grid parameters and boundary conditions (Fig. 3).

The boundary conditions used for solving the numerical model were defined as follows:

- The wind profile for low turbulence conditions was set at the inlet of flow according to the wind tunnel measurements indicated in Cheli et al. (2011alb). A uniform profile of $13.89 \mathrm{~m} / \mathrm{s}$ was imposed from the height of $2 \mathrm{~m}$ until the top wall of tunnel considering a scale model of 1:10. The components of wind speed in $Y$ and $Z$ directions are zero. The values for the turbulent length scale, $l$ and turbulence intensity, $I$ are $0.1 \mathrm{~m}$ and $2 \%$ respectively.

- An outlet pressure was imposed as a boundary condition at the outlet of flow from the domain. This condition allows the fluid to cross the boundary surface in either direction. The average relative pressure was set to $0 \mathrm{~Pa}$ and turbulent properties in back flow conditions were assigned with the values assigned at the inlet boundary.

- A non-slip wall $(U, V, W=0)$ was selected as a boundary condition for the solid surfaces (tunnel walls, truck, wind fences and embankment). The log-law region of fluid next to solid surfaces was solved using enhanced wall treatment instead of applying wall function because it is a more accuracy method to estimate the flow variables in this region.

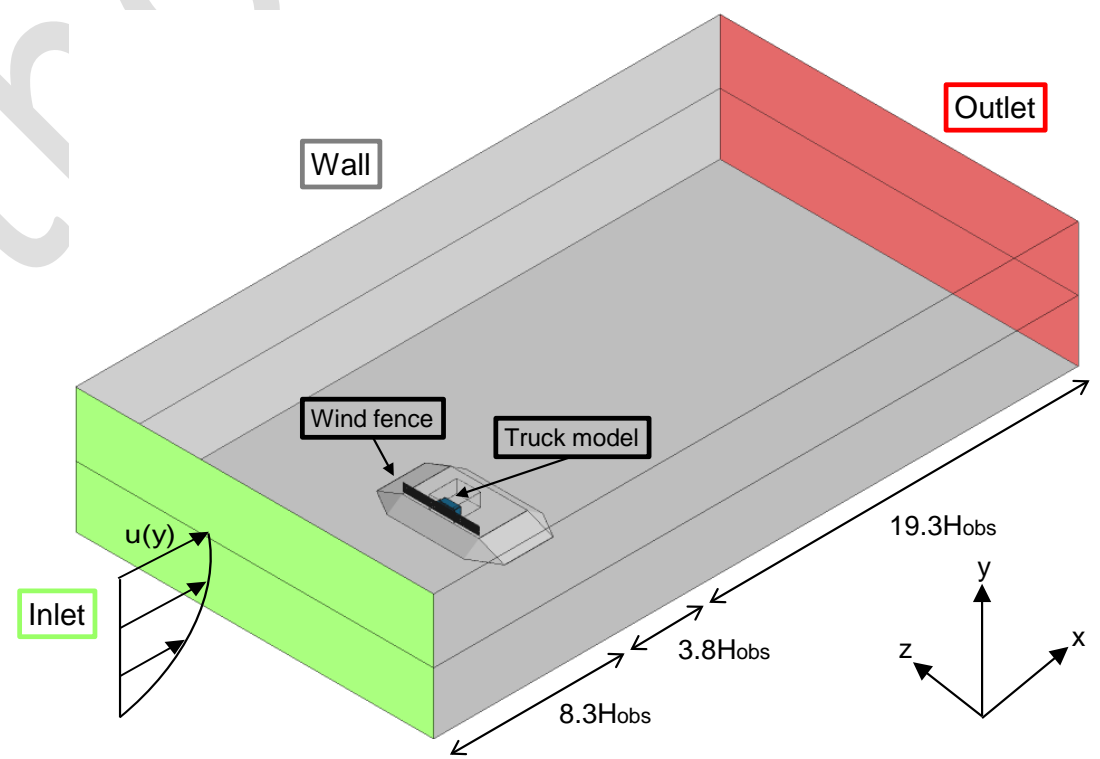

Fig. 3. Geometrical model and boundary conditions. 
A non-structural grid composed of tetrahedral was built for the far domain.1 and near domain and a structural grid composed of hexahedral was built for the far domain. 2 (Fig. 4). The grid of the near domain was finer than the far domains in order to capture the high gradients of the flow quantities due to the presence of the obstacles found by the air flow. In addition, an inflation grid was used to discretize the air region in contact with the truck and fence surfaces without slip due to its high accuracy in boundary layer zones (Fig. 4 (c), (d), (e) and (f)). A total of ten inflated layers with a growth rate of 1.05 make up the inflation grid, the thickness of the first layer being set to obtain a value of $y^{+} \leq 1$. The variable $y^{+}$is the dimensionless distance from the wall, related to the distance from the wall $y$, shear velocity $u_{\tau}$ and kinematic viscosity $v$ as follows:

$$
y^{+}=\frac{u_{\tau} \cdot y}{v}
$$
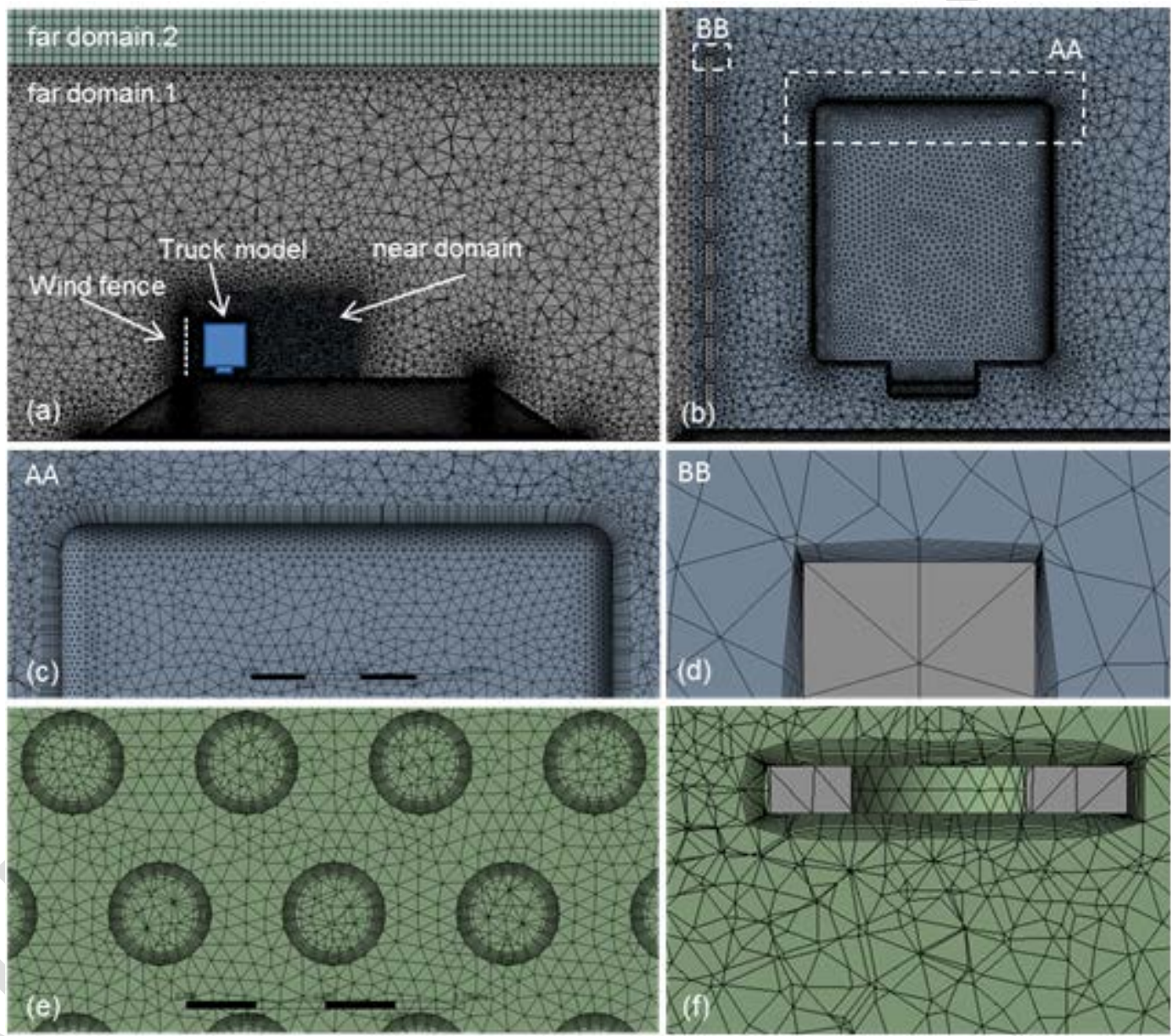

Fig. 4. Views of the grid in different air regions for the wind fence with rectangular slits and circular holes. (a) General view of the domains; (b) Grid in the near domain for the fence with rectangular slits; (c) Inflation grid near the truck surface; (d) Inflation grid near the surface of wind fence with rectangular slits and, (e) and (f) Inflation grid near the circular hole surface.

A higher accuracy in the results can be obtained by diminishing the cell size in the regions where strong gradients in the variables can happen. However, as the cell size diminishes the total number of cells in the grid rises and, in consequence the computational cost rises. Therefore, a grid size independence study was required to reach an appropriate balance between computational cost and accuracy. The number of cells 
was varied by means of refinement function acting on curvature surfaces and limiting the size of cells in the air regions around the truck and wind fence. Specifically, the aerodynamic coefficients acting on truck were calculated for two cases with respect to grid size, when none of the wind fence models was installed in the windward region of truck and, when the wind fence with circular holes was installed to protect the truck from the wind.

The variation of the aerodynamic coefficients as a function of the number of cells is shown in Fig. 5. From Fig. 5., it is possible to observe that the aerodynamic coefficients were quite steady for higher values of 5.4 mill and 3.4 mill of cells, in the case with the wind fence installed and without fence respectively. Thus, one of these two grid setups will be applied for the models where a wind fence model is included and the other grid setup for the cases without wind fence.

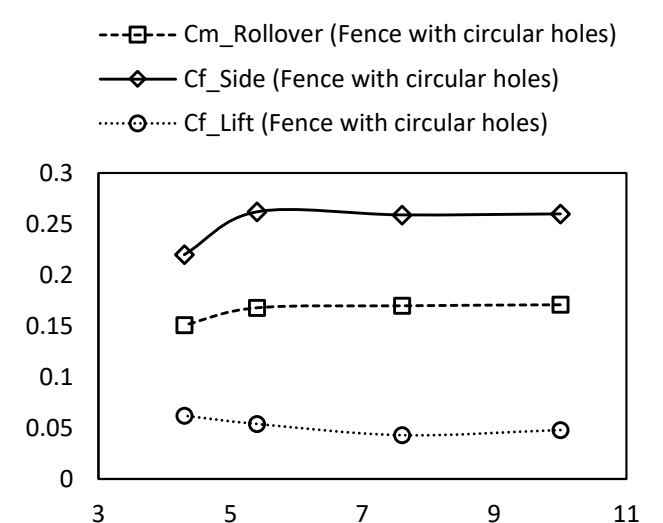

(a)

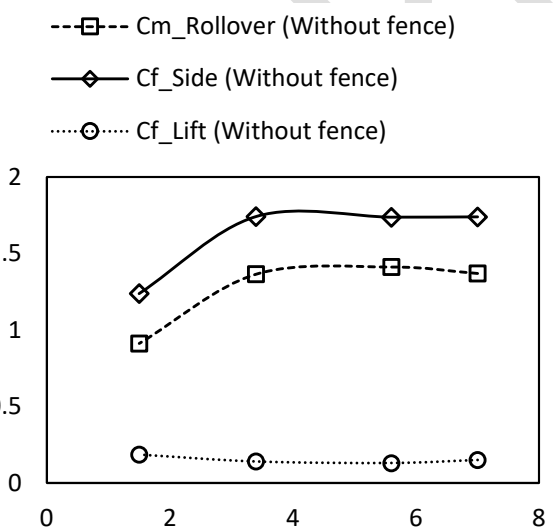

(b)

№ of Cells (mill)

Fig. 5. Effect of the number of cells on aerodynamic coefficients acting on the truck for two cases: (a) fence with circular holes and (b) without fence.

\section{Results and discussion}

In this section, the influence of different factors on vehicle stability is analyzed. Particularly, the effect of the following factors on aerodynamic coefficients was analyzed:

- Reynolds number.

- Type of wind fence model.

- Porosity of wind fence models.

- Truck position on road.

- Height of wind fence.

\subsection{Reynolds number effect}

The evolution of aerodynamic coefficients acting on the truck model was analyzed for a Reynolds number range between $1.37 \times 10^{5}$ and $7.2 \times 10^{5}$, in which the flow is still in the incompressible regime. The model studied consists on the truck model located on the embankment without the wind fence for a yaw angle of $90^{\circ}$ (crosswind conditions). The values of Reynolds number were obtained by means of the following expression: 


$$
\operatorname{Re}=\frac{\rho U_{\infty} L}{\mu}
$$

where the characteristic linear dimension, $L$ is equal to the reference height, $H$ used in the aerodynamic coefficients. According to Fig. 6, the values of aerodynamic coefficients acting on the truck model are quite constant from a Reynolds number equal to $2.5 \times 10^{5}$. In this respect, Cermak (1987) indicates that the onset of Reynolds number independence begins at a Reynolds number of $1.2 \times 10^{5}$ for bluff bodies. Therefore, the dynamic similarity between the 1/10 scaled-down model and the prototype in full scale can be considered as satisfied since the value of Reynolds number was $2.5 \times 10^{5}$ for every CFD models.

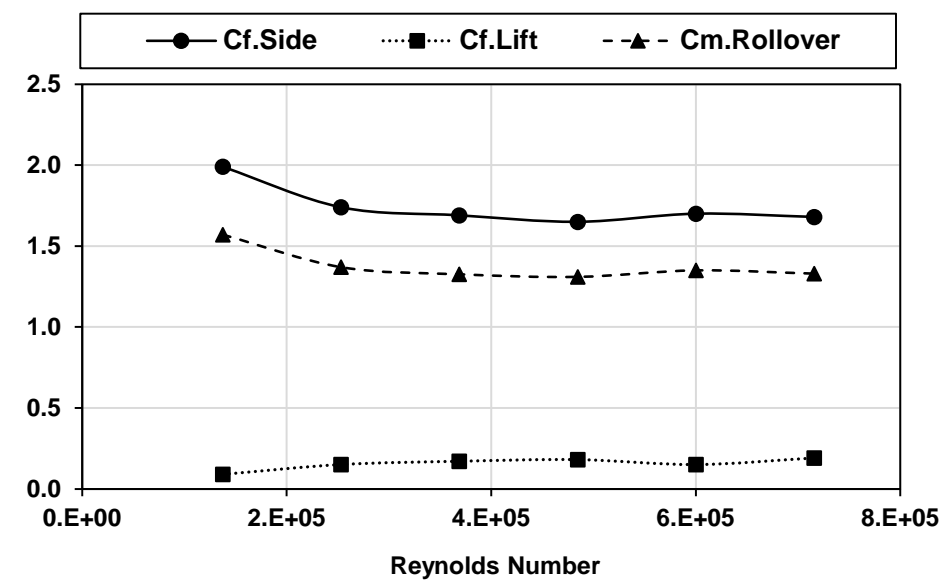

In order to analyze the effectiveness of the three wind fence models to improve the stability of a truck model under crosswind conditions, the aerodynamic coefficients acting on the truck were obtained for the wind fences proposed and without installing any protection. Specifically, the three wind fence models were designed with a porosity (porosity defined as the ratio between the open area and the total area of the fence) of $30 \%$ and a height of $4 \mathrm{~m}$ to compare them. Also, a numerical model including a solid fence (porosity equal to $0 \%$ ) was solved to compare its performance with the other types of wind fence. Fig. 7 exhibits the aerodynamic coefficients obtained for the different cases studied together with the experimental values from Cheli et al. (2011b) and Bocciolone et al. (2008). These studies were selected to validate the numerical model with experimental data without fence and with fence, since the turbulent characteristics of the air region around the truck are quite different when comparing the case without fence against the case with fence installed.

Moreover, the grid setup applied to solve the numerical models where a wind fence type was included, was the same than the applied by Alonso-Estébanez et al. (2016), where aerodynamic coefficients acting on bus located on bridge with crash barriers (1.25m of high at full scale and 35\% of porosity) installed, were obtained in crosswind conditions and compared with experimental data from Dorigatti et al., (2012). This along with the fact that the turbulent region in leeward side of the crash barriers should present similar characteristic to the region around the truck in some of the wind fence models studied in this 
work, it is possible to consider that the grid setup defined in section 2.4., should be suitable to efficiently solve the cases with wind fences included in the CFD model.

The rollover moment is the most influential aerodynamic coefficient on cross-wind stability (Schober et al., 2010), therefore the results indicate that the wind fence with circular holes shows a better performance than the other models for this value of porosity (Fig. 7). The rollover coefficient is lower in the case of installing a wind fence with circular openings than with rectangular openings, this may be due to less homogeneous distribution of open area. This causes that the contact surface parallel to the mainstream between the fluid and the wind fence increases, and as consequence higher values of viscous stress are approached in the air region close to the edge of holes. Therefore, the air flow loses more momentum quantity as it flows through the wind fence with circular holes, and thus, the side force coefficient acting on the truck is lower with respect to the wind fence with rectangular slits (Fig. 7). Particularly, the reduction in the rollover moment coefficients regarding the experimental reference are: $77.14 \%$ for wind fence with plates, $87.86 \%$ for wind fence with circular holes and $81.43 \%$ for wind fence with rectangular slits.

On the other hand, the biggest relative differences between the numerical model and the experimental data from Cheli et al. 2011b are obtained for the lift aerodynamic coefficient. This could be because all geometric details of the bottom truck part from experimental study were not kept in the numerical simulation in order to reduce the grid size and thus the computational cost. As a consequence, the characteristics of airflow under the truck can vary and the lift force obtained by numerical simulation may differ from the experimental value. In the case of solid fence, it is possible to observe that the numerical results are relatively similar to experimental results from Bocciolone et al. (2008).

The numerical results in relation to the pressure and velocity in the air region around both the truck and the wind fence models under crosswind conditions are shown in Fig. 8. From these results, good performance of wind fence models studied can be appreciated in reducing the aerodynamic loads acting on the truck with respect to the case without wind fence. The wind fence models cause a reduction of wind speed in the air region near the windward side of truck, protecting the truck from the impact of highspeed streamlines (Fig. 8). Specifically, the difference in pressure between the windward side and leeward side of the truck is slightly higher for the wind fence with plates with respect to the other wind fence models, as a consequence of this, the side force is also greater according to the results previously indicated. Also, the lift force of the truck is higher for the model with plates, because the pressure acting on the bottom left of truck reaches higher positive values due to the air flow is channeled through the bottom gap between last plate and the ground. As consequence of this, the air velocity in the bottom gap of the truck approaches higher values for this wind fence model (Fig. 8). On the other hand, the presence of a wind fence modifies strongly the behavior of air flow before reaching the truck. Specifically, the wind fence induces a highly turbulent region in the windward side of truck and therefore the pressure acting on this surface may be negative for low values of porosity, while without the wind fence the pressure is positive. 


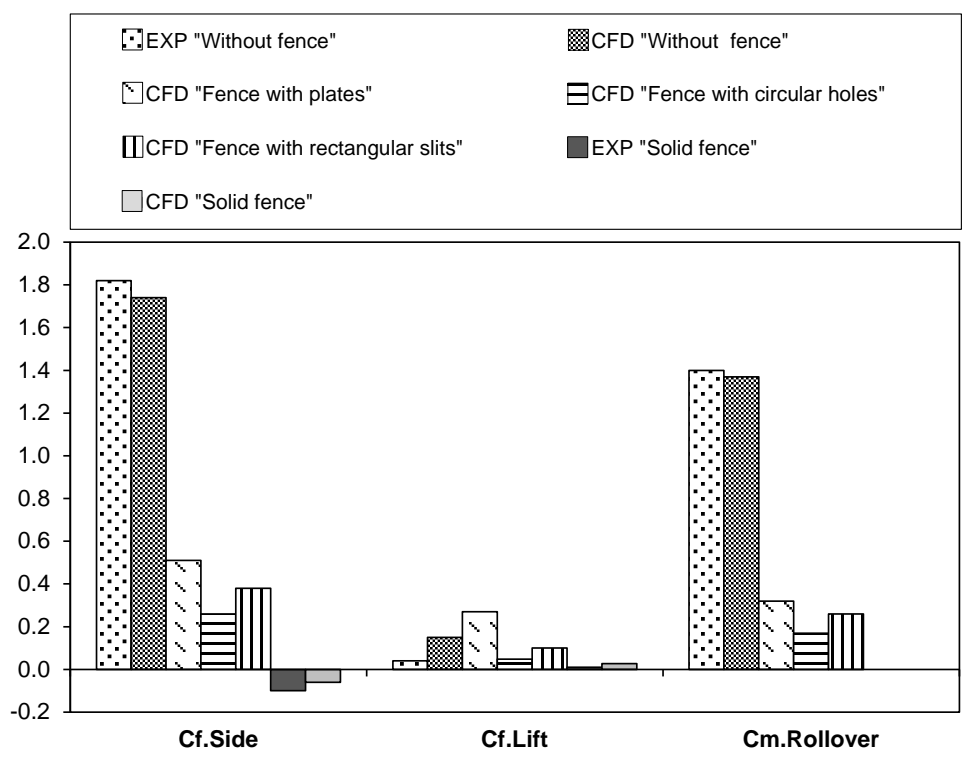

Fig. 7. Comparison of aerodynamic coefficients with perpendicular wind $\left(\gamma=90^{\circ}\right)$, obtained by numerical modeling (CFD) for all cases studied and, only by wind tunnel tests for the cases without fence (Cheli et al., 2011b) and with solid fence (Bocciolone et al., 2008).
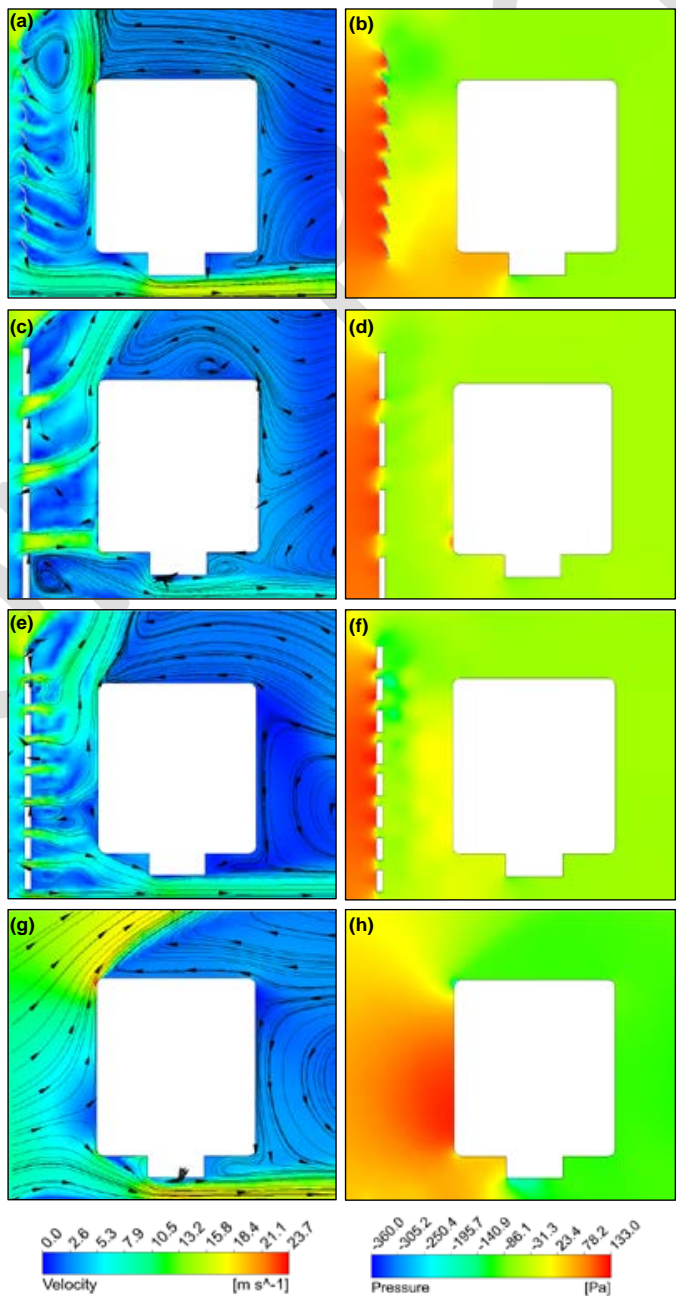

Fig. 8. Velocity and pressure contours calculated from numerical model results for the following cases: wind fence with plates (a) and (b); wind fence with circular holes (c) and (d); wind fence with rectangular slits (e) and (f) and without wind fence (g) and (h). 
In this section, the relationships between the aerodynamic coefficients studied and the porosity is obtained for the three wind fence models analyzed. Specifically, the values of porosity studied for the wind fences with circular and rectangular slits were: $0 \%, 10 \%, 20 \%, 30 \%, 40 \%$ and $50 \%$. In these wind fence models the porosity values were adjusted by modifying the diameter of the circular openings and the width of the boards. While in the case of wind fence model with plates the porosity values studied were: $26.7 \%, 30 \%$ and $41.8 \%$. These values were obtained from the design of experiment by modifying the rotation angle of plate parameter, $\Delta \delta$. The value of porosity which provides a great protection against a possible rollover accident is considered as the optimum value. Therefore, the aerodynamic coefficients shown in Fig. 9 as a function of porosity indicate the optimum values of porosity are located in the range $0 \%-10 \%$ for the wind fences with circular and rectangular slits. Particularly, this is so for truck positions relatively close to the wind fence as shown in Fig 10. In the case of wind fence with plates, the optimum value of porosity is $26.7 \%$ for the range of values studied; however, it is likely that lower values of porosity provide a better protection for relatively small distance between the truck and the wind fence.

317 On the other hand, when comparing the wind fences models with circular and rectangular open areas the aerodynamic coefficients exhibit similar trends in the porosity range analyzed, however, the circular shape of holes provides a greater reduction of rollover moment in every values of porosity studied. In addition, this differences of rollover moment are smaller as the porosity decreases. In the case of wind fence with plates, the rollover moment coefficient appears to exhibit greater variation with of porosity in comparison with the other wind fence models in the same range of porosity. The intensity of turbulence in the leeward side of the wind fence rises with lower values of porosity and this cause that suction force acting on the windward surface of truck increases. Accordingly, the side force and rollover moment values can be negative for low values of porosity as it is happen in this case (Fig. 9). The rollover coefficient shows a trend against the porosity quiet similar to the side coefficients for all wind fence models studied because the side force has a greater influence in the rollover moment than the lift force. In relation to the lift coefficient, this coefficient decreases as porosity diminishes for the wind fence models with rectangular slits and circular holes but it does not in the case of wind fence with plates.

330 On the other hand, the effect of distance between the wind fence of $4 \mathrm{~m}$ height with circular holes and the truck position was also studied for several values of porosity. Specifically, the aerodynamic coefficients

332 acting on the truck were calculated for five values of porosity in the range from $10 \%$ to $30 \%$ under crosswind conditions. In Fig. 10, the reduction of rollover coefficient with respect to the case without

334 fence as function of the horizontal distance between the truck and wind fence, is shown for the range of 335 porosity indicated. In the reference case, without wind fence, the distance between the truck position and crest of embankment is the same as in the case where the truck position is closer to the fence $(1.07 \mathrm{~m})$. From Fig. 10, it is possible to discern that the influence of porosity on rollover reduction is stronger for truck positions closer to the wind fence. The rollover reduction increases with the separation distance between the truck and wind fence, even, the rollover moment coefficient reaches negative values for a 

obtained for the lowest value of porosity, 10\% (Fig. 10).

- "Wind fence with plates"

- "Wind fence with rectangular slits"

$\triangle$ "Wind fence with circular holes"

(a)
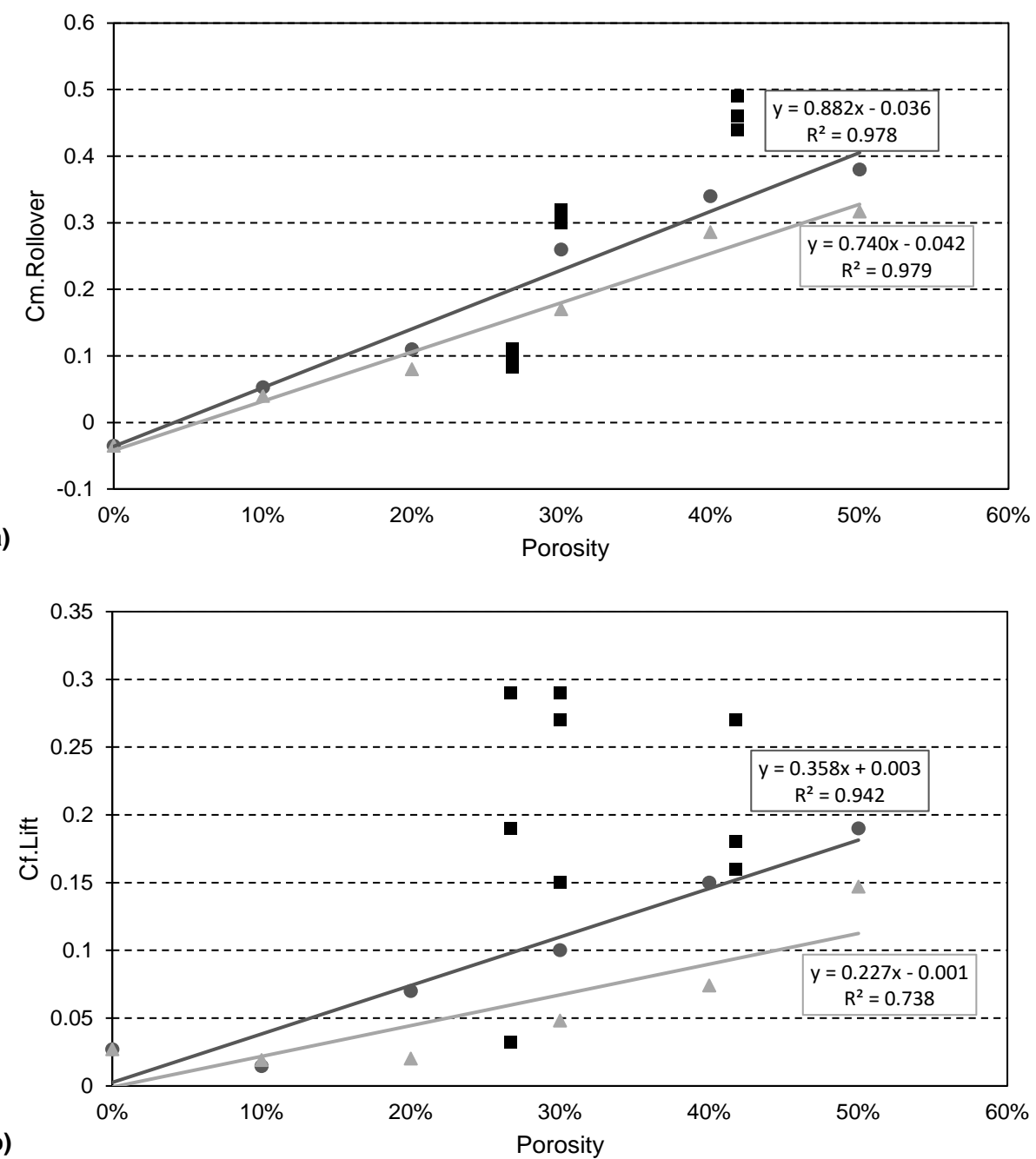

(b)

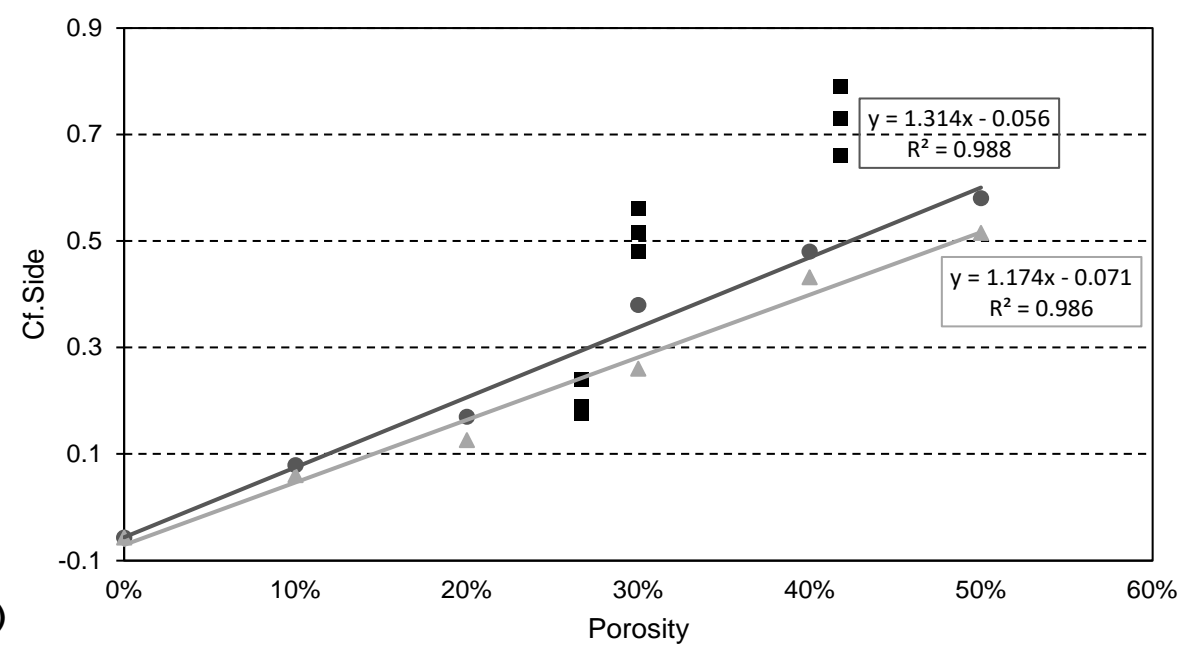

(c)

Fig. 9. Aerodynamic coefficients depending on the porosity for the wind fence of $\mathbf{4} \mathbf{m}$ height and with circular holes. (a) Rollover moment; (b) Lift force; (c) Side force. 


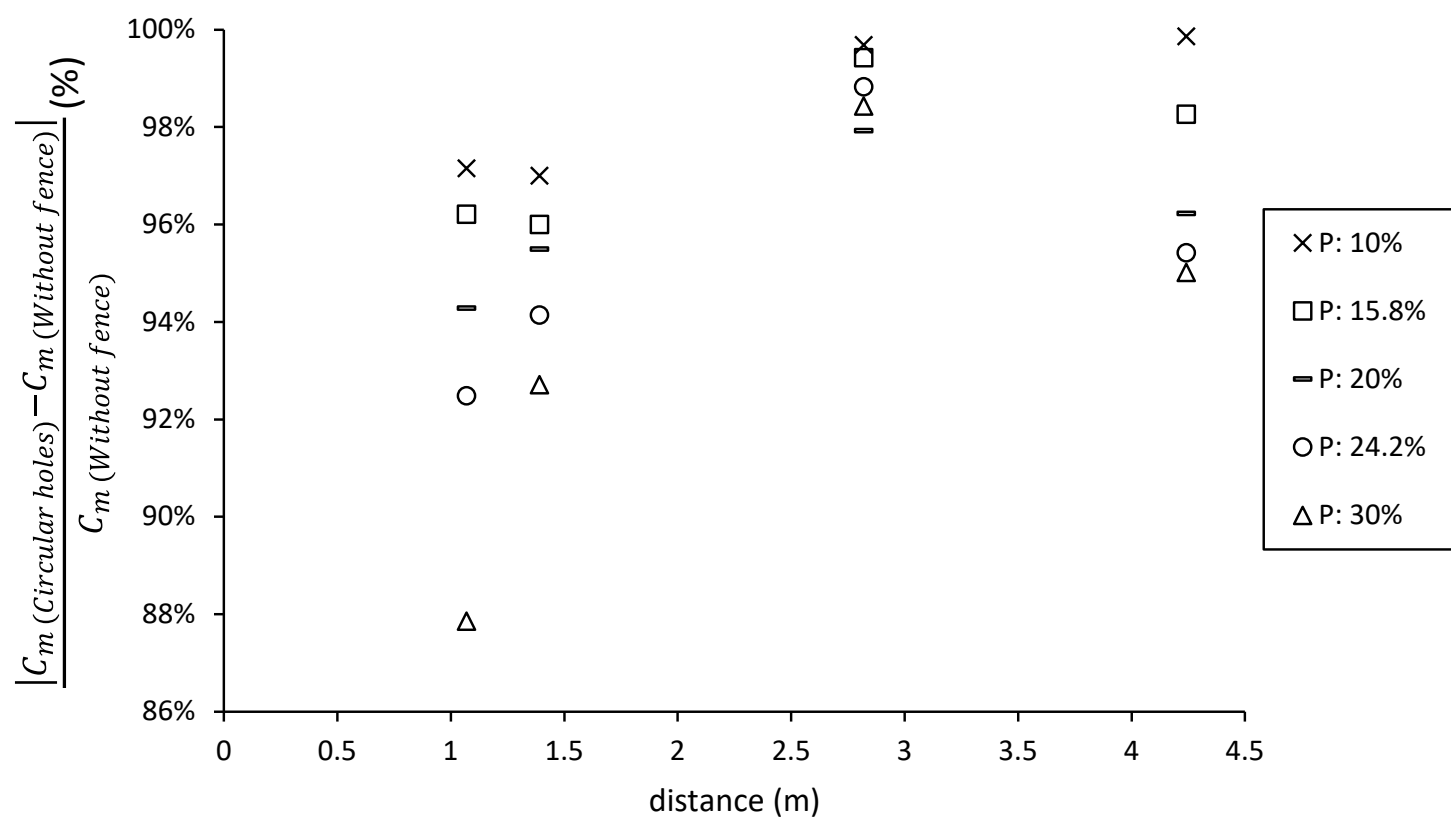

Fig. 10. Relationship between the separation distance between the wind fence and truck position and the rollover reduction for several values of porosity.

\subsection{Effect of the fence height with respect to the truck position}

350

Another parameter of the wind fences that was studied in relation to its effect on truck aerodynamic is the height of wind fence. This parameter could be as important as the porosity of wind fence in the protection of traffic against adverse wind conditions. The wind fence used for this study was the wind fence with circular holes keeping its porosity equal to $20 \%$ for the four values of height proposed: $4 \mathrm{~m}, 3 \mathrm{~m}, 2 \mathrm{~m}$ and $1 \mathrm{~m}$. Fig. 11 presents the aerodynamic coefficients of truck as a function of the distance between the truck position and the wind fence for the fence height values proposed. From Fig. 11, it is possible to observe that the values of rollover coefficient are quite similar for all height values evaluated except for $1 \mathrm{~m}$ of height. Specifically, the wind fence of $1 \mathrm{~m}$ height provides the lowest level of protection against the crosswind for truck positions relatively close to the wind fence. In fact, the reduction of rollover coefficient is equal to $78.5 \%$ when the wind fence height is increased from $1 \mathrm{~m}$ to $2 \mathrm{~m}$ for the truck position closer to the wind fence $(1.07 \mathrm{~m})$. Fig. 12 shows that a great portion of streamlines from the embankment slope hit on the windward surface of truck for a fence height of $1 \mathrm{~m}$, whereas for $2 \mathrm{~m}$ of fence height the streamlines pass mostly over the truck. The rollover coefficient differences obtained for the wind fence height of $1 \mathrm{~m}$ and the other values of height evaluated decrease with the increase of distance between the fence and truck (Fig 12).

366 Another aspect to be noted is that a wind fence with a height of $2 \mathrm{~m}$ can provide a similar level of protection against crosswind than a wind fence with a height of $4 \mathrm{~m}$, considering both the truck size and its position on the road studied. With regard to the lift coefficient, the values of this coefficient were quite similar in the distance range evaluated for $3 \mathrm{~m}$ and $4 \mathrm{~m}$ of fence height, while strong variations were obtained in the lift coefficient for lower values of fence height, as shown in Fig. 11. On the other hand, the effect of the distance between the truck position and the wind fence on the rollover coefficient is 
372 relatively strong for the fence height of $1 \mathrm{~m}$ and quite softer for the other fence height values evaluated 373 (Fig. 12).
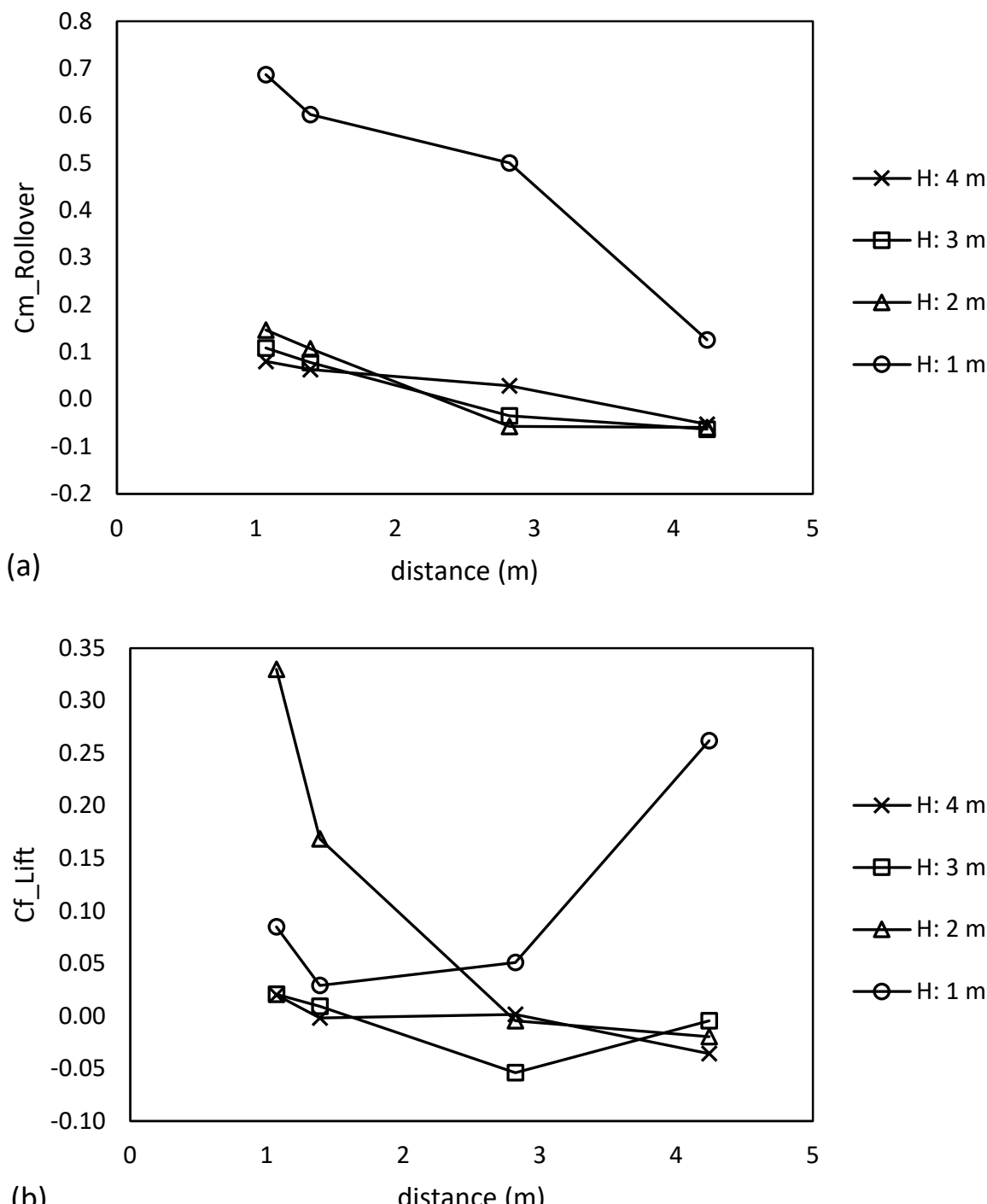

(b)

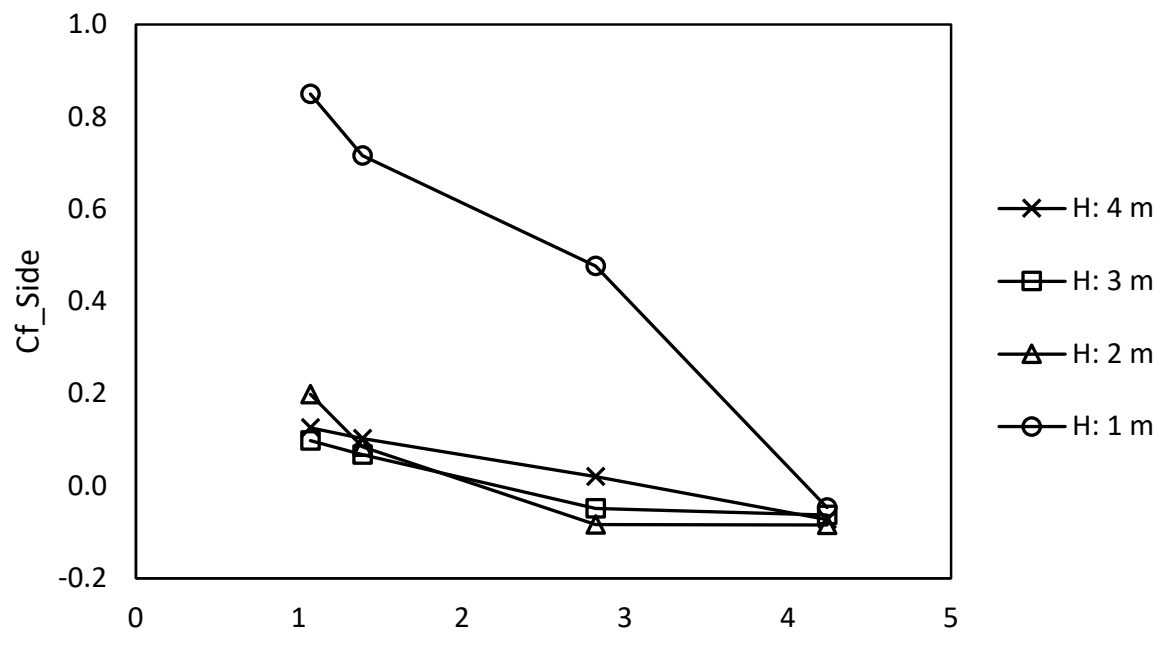

(c)

distance $(m)$

Fig. 11. The relationships between the aerodynamic coefficients of truck and the distance in full scale between the wind fence and the truck position for several values of wind fence height. 

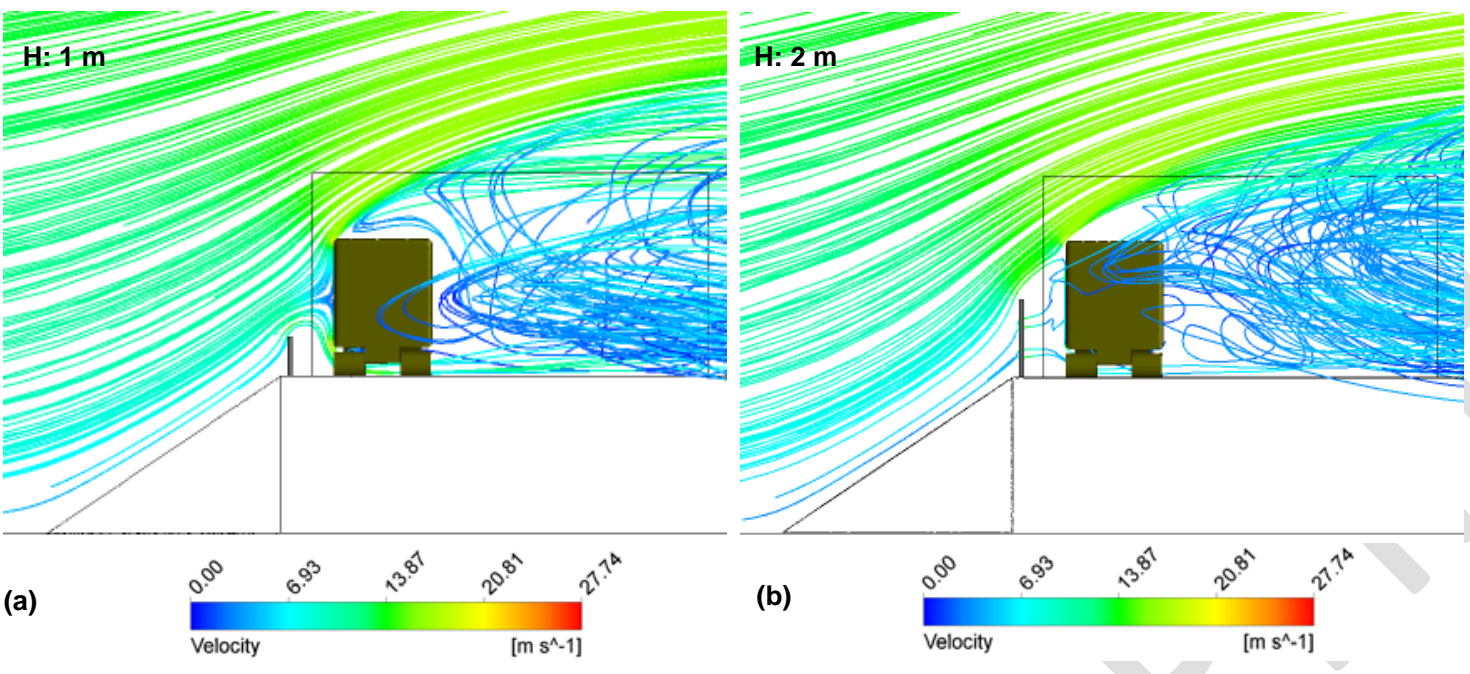

(a)
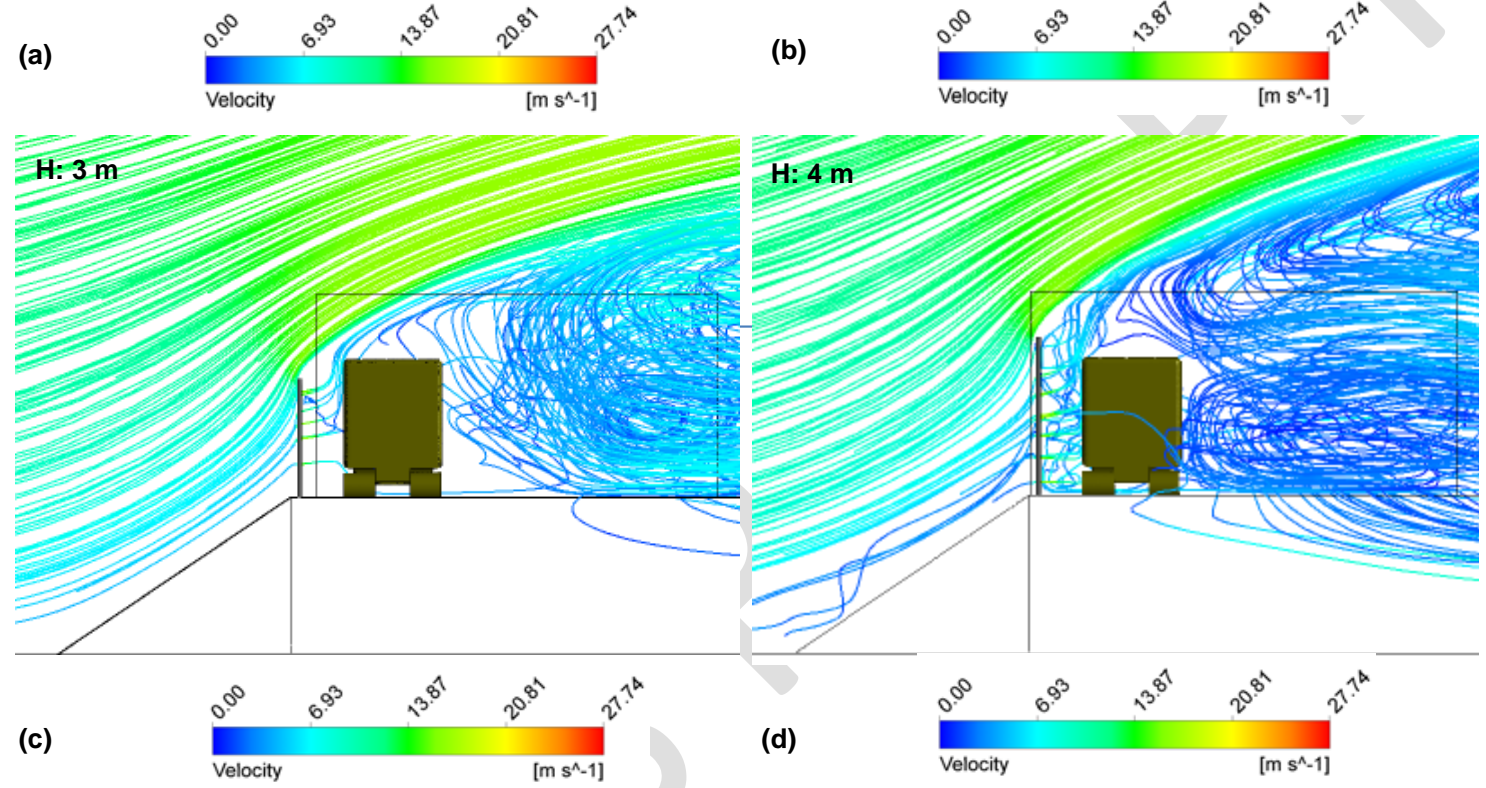

Fig. 12. Streamlines of velocity field around of truck for four values of wind fence height: (a) $1 \mathrm{~m}$; (b) $2 \mathrm{~m}$; (c) $3 \mathrm{~m}$ and (d) $4 \mathrm{~m}$.

\section{Discussion}

In this work, the wind fence performance is studied when it is installed in the crest of an embankment, but if the wind fence was located in a flat ground, lower aerodynamic coefficients acting on the truck should be obtained, particularly in comparison with the truck position closer to the wind fence. In fact, the overspeeding coefficient $f_{E M B, F G}$ used to transform the flat ground coefficients to the embankment coefficients is 1.23 according to the RIL 80704 (DB NetzAG,2006). Therefore, keeping the same type of wind fence for both infrastructures (flat ground and embankment), the aerodynamic coefficients acting of truck should be lower in the flat ground in comparison with truck positions relatively closer to the embankment crest.

On the other hand, aerodynamic coefficients were obtained for a yaw angle of $90^{\circ}$ (the wind velocity relative to the vehicle is perpendicular to vehicle velocity) because is one of the most critical values, as it is indicated in Cheli et al., (2011b). However, higher values of rollover coefficient could be obtained for other yaw angle values when a wind fence is installed, as it happens in Bocciolone et al., (2008) where the 
highest value of rollover coefficient was obtained for yaw angle of $70^{\circ}$ using a porous fence. It can be due to the streamlines of velocity field cover a greater length of embankment slope for this yaw angle value than in the case of perpendicular flow to the embankment slope, and hence, a higher acceleration of streamlines is obtained and this counteracts the lack of perpendicular wind component.

401

402

403

The wind fence can be also used as snow fence, both for avoiding the snowdrift and the formation of ice on roads, and to improve the visibility of drivers during blizzards (Tabler, 2005). The leeward side of the wind fence relatively near it is characterized by the vortex presence where the kinetic energy of air flow is dissipated. In consequence, the air flow losses a predominant wind direction and does not retain enough kinetic energy to transport snow particles due to its own weight and the snow drops on this region and is accumulated. The length and depth of the snow deposit zone varies with geometry parameters of wind fences such as the porosity and the bottom gap (open area between the ground and the fence). On the one hand, a higher value of porosity increases the air velocity in the leeward region of wind fence and hence the depth of snowdrift diminishes due to the stronger erosion caused by the air stream while, on the other hand, the extension of snowdrift region increases. Tabler (2006) indicates that for flat terrain the fences should be placed at a distance of at least 35 times the fence height from the area to be protected as measured in the direction of the predominant wind.

414 The bottom gap assists to reduce the deposition of snow in the immediate vicinity of the fence because the air flow is accelerated when it crosses the bottom gap, delaying the snowdrift and also avoiding that the wind fence will be buried later. Specifically, the effect of the air flow from the bottom gap is to sweep away the snowdrift on the road. Accordingly, if the wind fences studied in this work were installed in embankments where snow is frequently accumulated on the road, porous wind fences including a bottom gap would be a better option to be installed in comparison to a solid fence. In particular, highest values of porosity and bottom gap size decrease the snow accumulation rate, however, the effect of bottom gap on clean region of snow is stronger than the fence porosity according to Liu et al. (2016). The bottom gap of snow fence must be between $10 \%$ and $15 \%$ of the total fence height for cleaning properly of snow the surface immediately downwind of the fence (Sañudo-Fontaneda et al. 2011; Tabler, 2005). Wind fence models whose main function is to protect the traffic against the wind action, can rise the bottom gap size to improve the sweeping effect provided of course that a gap size relatively great does not compromise vehicle stability under crosswind conditions.

427 In this study, the wind fence models are located on the crest of embankment close to the road, without 428 respecting the distance of $35 \mathrm{H}$ ( $\mathrm{H}$ is the fence height) indicated in Tabler (2006), since these models are 429 focused on protecting the traffic from the crosswind and, not on storing snow far from the road. 430 Therefore, in regions where snowfalls are common, the wind fence model with plates can be considered a 431 better option against the other models, because the plates can be oriented to channel the air flow in the 432 same direction of bottom flow and strengthen the sweeping effect as it is shown in García Nieto et al. 433 (2010). This measure should reduce the amount of accumulated snow on roads and to improve the traffic 434 safety particularly for cold regions around the world. 


\section{Conclusions}

In the present work, the performance of three wind fence models to protect a truck model in crosswind conditions is analyzed. Furthermore, the influence of characteristic parameter of wind fence (porosity and height) on the aerodynamic coefficients of truck for four values distance between the truck and the fence is studied. From the results obtained, the following conclusions can be drawn:

1. The similarity conditions between the model and prototype were satisfied in the study.

2. The wind fence with circular holes exhibits a greater efficacy than the model with rectangular slits for the range of porosity analyzed.

3. The rollover coefficient acting on the truck decreases when the porosity of wind fence models studied diminishes. Specifically, the optimum values of porosity are located in the range $0 \%$ $10 \%$ for the wind fences with circular and rectangular open areas. In the case of model with plates, it shows a better performance for the lower value of porosity studied, $26.7 \%$.

4. The effect of porosity on rollover reduction is stronger for truck positons closer to the wind fence model.

5. The rollover coefficient diminishes with the separation distance between the truck and wind fence, even, a negative value is obtained for a distance of $4.24 \mathrm{~m}$, where the turbulent flow is predominant.

6. The rollover coefficient values are quite similar for all values of fence height evaluated except in the case of wind fence of $1 \mathrm{~m}$ height, where the highest values of rollover coefficient are obtained. In fact, a reduction of rollover coefficient of $78.5 \%$ is obtained when the wind fence height raises from $1 \mathrm{~m}$ to $2 \mathrm{~m}$ for the truck positions closer to the wind fence.

7. The rollover coefficient differences between the values estimated for a fence height of $1 \mathrm{~m}$ and for the other values of height ( $2 \mathrm{~m}, 3 \mathrm{~m}$ and $4 \mathrm{~m}$ ) decrease with the distance between the wind fence and truck.

8. The effect of the distance between the truck position and the wind fence on the rollover coefficient, is quite stronger for the lowest value of wind fence height evaluated. A wind fence with a height of $2 \mathrm{~m}$ can provide a similar level of protection against rollover accident than a wind fence with a height of $4 \mathrm{~m}$, considering the studied truck size and for truck positions relatively close to the fence. 
9. The wind fences models installed in the embankments where the snowdrift on road is usual, should include a bottom gap to minimize the adverse effect both of the accumulation of snow and the formation of ice on the traffic safety.

10. A higher size of bottom gap decreases the amount of snow accumulated in surface immediately downwind of the fence, however an excessive increase of this gap can compromise the vehicle stability due to an increasing of aerodynamic loads acting on it in crosswind conditions. Several researchers recommend a value of bottom gap between $10 \%$ and $15 \%$ for fences used to control snowdrift on road.

This work was supported by the OASIS Research Project that was co-financed by CDTI (Spanish Science and Innovation Ministry) and developed with the Spanish companies: Iridium, OHL Concesiones, Abertis, Sice, Indra, Dragados, OHL, Geocisa, GMV, Asfaltos Augusta, Hidrofersa, Eipsa, PyG, CPS, AEC and Torre de Comares Arquitectos S.L. and 16 research centres. The authors would also like to thank the GICONSIME research group of the University of Oviedo (Spain) for their collaboration in this research. 
Alonso-Estébanez, A., Del Coz Díaz, J.J., Álvarez Rabanal, F.P., Pascual-Muñoz, P. 2016. Numerical simulation of bus aerodynamics on several classes of bridge decks. Engineering Applications of Computational Fluid Mechanics. 1-15. DOI: 10.1080/19942060.2016.1201544.

ANSYS User Manual (2015). ANSYS, Inc. Canonsburg, PA.

Andersson, B.; Andersson, R.; Hakansson, L.; Mortensen, M.; Rahman, S.; and Berend, V.W. 2011. Computational fluid dynamics for engineers. Cambridge University Press, New York, USA. ISBN: 9781107018952.

Argentini, T.; Ozkan, E.; Rocchi, D.; Rosa, L.; Zasso, A. 2011. Cross-wind effects on a vehicle crossing the wake of a bridge pylon, J.Wind Eng.Ind.Aerodyn. 99(6-7): 734-40. DOI:10.1016/j.jweia.2011.01.021.

Bitog, J. P.; Lee, I. -B.; Shin, M. -H.; Hong, S. -W.; Hwang, H. -S.; Seo, I. -H.; Yoo, J. -I.; Kwon, K. -S.; Kim, Y. H.; Han, J. -W. 2009. Numerical simulation of an array of fences in saemangeum reclaimed land, Atmos.Environ. 502 43(30): 4612-21. DOI: 10.1016/j.atmosenv.2009.05.050.

Bitsuamlak, G. T.; Stathopoulos, T.; Bédard, C. 2004. Numerical evaluation of wind flow over complex terrain: Review, J.Aerospace Eng.17(4): 135-45. DOI: 10.1061/(ASCE)0893-1321(2004)17:4(135).

Bocciolone, M.; Cheli, F.; Corradi, R.; Muggiasca, S.; Tomasini, G. 2008. Crosswind action on rail vehicles: Wind induced loads-Part 1, J.Wind Eng.Ind.Aerodyn, 99 (10): 1000-1010. DOI: 10.1016/j.jweia.2011.07.009.

Cheli, F.; Ripamonti, F.; Sabbioni, E.; Tomasini, G. 2011. Wind tunnel tests on heavy road vehicles: Cross wind induced loads-Part 2, J.Wind Eng.Ind.Aerodyn, 99 (10): 1011-1024. DOI: 10.1016/j.jweia.2011.07.007.

Delaunay, D.; Baker, C. J.; Cheli, F.; Morvan, H.; Berger, L.; Casazza, M.; Gomez, C. 2006. Development of wind of the SIRWEC2006, 13th International Riad Weather Conference.

519 Dong, Z.; Luo, W.; Qian, G.; Wang, H. 2007. A wind tunnel simulation of the mean velocity fields behind upright 520 porous fences, Agric.For.Meteorol.146(1-2): 82-93. DOI: 10.1016/j.agrformet.2007.05.009.

Dorigatti, F.; Sterling, M.; Rocchi, D.; Belloli, M.; Quinn, A.D.; Baker, C.J.; Ozkan, E. 2012. Wind tunnel measurements of crosswind loads on high sided vehicles over long span bridges. J. Wind Eng. Ind. Aerodyn, 107108: 214-224. DOI: http://dx.doi.org/10.1016/j.jweia.2012.04.017.

524 Guo, W.; Wang, Y.; Xia, H.; Lu, S. 2015. Wind tunnel test on aerodynamic effect of wind barriers on train-bridge system, Sci China Technol Sci, 58 (2): 219-225. DOI: http://dx.doi.org/10.1007/s11431-014-5675-1.

Hoppmann, U.; Koenig, S.; Tielkes, T.; Matschke, G. 2002. A short-term strong wind prediction model for railway application: Design and verification, J.Wind Eng.Ind.Aerodyn. 90(10): 1127-34. DOI: 10.1016/S0167528 6105(02)00226-X. 
Kim, H. B.; Lee, S. J. 2002. The structure of turbulent shear flow around a two-dimensional porous fence having a bottom gap, J.Fluids Struct. 16(3): 317-29. DOI: 10.1006/jfls.2001.0423.

Li, W.; Wang, F.; Bell, S. 2007. Simulating the sheltering effects of windbreaks in urban outdoor open space, J.Wind 535 Eng.Ind.Aerodyn. 95(7): 533-49. DOI: 10.1016/j.jweia.2006.11.001.

536 Lin, X. -J.; Barrington, S.; Choinière, D.; Prasher, S. 2007. Simulation of the effect of windbreaks on odour 537 dispersion, Biosyst. Eng.98(3): 347-63. DOI: 10.1016/j.biosystemseng.2007.07.010.

538 Liu, D.; Li, Y.; Wang, B.; Hu, P.; Zhang, J. 2016. Mechanism and effects of snow accumulations and controls by 539 lightweight snow fences, J. Mod. Transport. 24(4): 261-269. DOI 10.1007/s40534-016-0115-5.

Mathieu J.; Scott J. 2000. An introduction to turbulent flow. Cambridge: Cambridge University Press, 374 p. ISBN13: 978-0521775380.

Matsuzawa, M.; Kajiya, Y.; Takeuchi, M. 2005. The development and validation of a method to estimate visibility

Menter F.R. 1993. Zonal Two Equation Turbulence Models for Aerodynamic Flows, 23rd Fluid Dynamics, 545 Plasmadynamics, and Lasers Conference, AIAA Paper: 93-2906. DOI: 10.2514/6.1993-2906. 32(8): 1598-1605. DOI: 10.2514/3.12149.

Park, C. W.; Lee, S. J. 2001. The effects of a bottom gap and non-uniform porosity in a wind fence on the surface 10.1016/S0167-6105(01)00105-2.

Pope, S. B. 2000. Turbulent flows. $1^{\text {st }}$ Edition. Cambridge: Cambridge University Press, 771 p. ISBN: 0-521-598869.

Ranade, V.V. 2002. Computational Flow Modeling for Chemical Reactor Engineering. Academic Press, 480 p. ISBN -10: 0125769601.

Santiago, J. L.; Martín, F.; Cuerva, A.; Bezdenejnykh, N.; Sanz-Andrés, A. 2007. Experimental and numerical study of wind flow behind windbreaks, Atmos.Environ. 41(30): 6406-20. DOI:10.1016/j.atmosenv.2007.01.014.

Sañudo-Fontaneda, L.A.; Castro-Fresno, D.; Del Coz-Díaz, J.J.; Rodriguez-Hernandez, J. 2011. Classification and comparison of snow fences for the protection of transport infrastructures, Journal of Cold Regions Engineering. 25(4): 162-181. DOI: 10.1061/(ASCE)CR.1943-5495.0000031. three standard ground scenarios, J.Wind Eng.Ind.Aerodyn. 98(6-7): 345-52. DOI: 10.1016/j.jweia.2009.12.004.

Shao, X. M.; Wan, J.; Chen, D. -W.; Xiong, H. -B. 2011. Aerodynamic modeling and stability analysis of a highspeed train under strong rain and crosswind conditions, Journal of Zhejiang University: Science A 12(12): 964-70. DOI: 10.1631/jzus.A11GT001.

Tabler, R. D. 2005. Controlling blowing snow with snow fences. How to control blowing and drifting snow with snow fences and road design. Gov. Eng., Jul./Aug., 30-32.

Tabler, R. D. 2006. Three-dimensional roughness elements for snow retention. Wyoming Dept. of Transportation, Cheyenne, WY. passenger railway operation in germany: The new DB guideline ril 80704, Proceedings of the Eighth World Congress 
574 Torita, H.; Satou, H. 2007. Relationship between shelterbelt structure and mean wind reduction, 575 Agric.For.Meteorol.145 (3-4): 186-94. DOI: 10.1016/j.agrformet.2007.04.018.

576 Tuzet, A.; Wilson, J. D. 2007. Measured winds about a thick hedge, Agric.For.Meteorol.145 (3-4): 195-205. DOI: 577 10.1016/j.agrformet.2007.04.013.

578 Tu, J.; Yeoh, G.H.; Liu, C. 2008. Computational Fluid Dynamics: A Practical Approach, $2^{\text {nd }}$ Edition. Burlington: 579 Butterworth-Heinemann, 456 p. ISBN-13: 978-0080982434.

580 Yeh, C. -P.; Tsai, C. -H.; Yang, R. -J. 2010. An investigation into the sheltering performance of porous windbreaks 581 under various wind directions, J.Wind Eng.Ind.Aerodyn. 98 (10-11): 520-32. DOI: 10.1016/j.jweia.2010.04.002.

582 Zhu, L.D.; Li, L.; Xu, Y.L.; Zhu, Q. 2012. Wind tunnel investigations of aerodynamic coefficients of road vehicles on 583 bridge deck. J. Fluids Struct., 30: 35-50. DOI: 10.1016/j.jfluidstructs.2011.09.002.

584 Zienkiewicz, O.C.; Taylor, R.L.; Nithiarasu, P. 2005. The finite element method for fluid dynamics. New York: 585 Butterworth-Heinemann, 400 p. ISBN-13: 978-0750663229. 